\title{
The Impact of Economics and Finance Research published in Central and Eastern Europe
}

\author{
Thomas M. Krueger \\ Texas A\&M University - Kingsville, TX, USA \\ Nikolay Megits \\ Webster University, St. Louis, MO, USA
}

\begin{abstract}
Research quality dictates the reputation of faculty, colleges, and universities, regardless of their location. In order to shed some light on the quality construct, this research reports on the scholarly impact of economics and finance (E\&F) journals published in countries of Central and Eastern Europe (CEE). A comparison of coverage by Web of Science (WoS), Scopus, and Cabell's, three scholarly databases, reveals the lesser coverage of CEE journals within WoS and Scopus. Examination of E\&F journals published in Poland, Romania, and the remainder of CEE, as defined by the Journal of Eastern European and Central Asian Research, discloses that the level of quality varies by nation. There are variations across the popular CiteScore, SJR, SNIP, and percentage of articles cited bibliometric measures. Furthermore, this research documents the existence of impact variation between journals focused on Eastern Europe published in Eastern Europe and published elsewhere in the world. Insights regarding both journal characteristics and review procedures will be of great value in assessing the impact of E\&F performance of research of scholars, whether or not they reside in Eastern Europe.
\end{abstract}

Keywords: Economics, Finance, Impact Factor, CiteScore, SJR, SNIP, Scopus, Web of Science, Cabell's, Central and Eastern Europe

DOI: http://dx.doi.org/10.15549/jeecar.v8i1.647

\section{INTRODUCTION}

The Central and Eastern European (CEE) region has experienced an extraordinary 30-year political and economic revival. These changes have had a direct impact on academic life and research productivity, raising concerns regarding the scholarly impact of journals authored by the region's scholars. Making the analysis all the more complex in these mostly post-socialist countries, is that government frequently still has a direct impact on university life and regulates academic research and the publication process. For instance, in this region, being published in journals indexed in Scopus, is a key requirement in order to be allowed to defend a doctoral dissertation. Under these conditions, what is the reputation and impact of research published in Eastern Europe? In order to gain insight to this 
question, this article reports on a study of the impact made by economics and finance journals (E\&F) published in CEE.

The ability to find and place E\&F journals is a critical component of this research. Since its founding in 1978, E\&F professors have relied upon Cabell's Directory of Publishing Opportunities as their biblical listing of journals in which to publish, with accompanying journal information. By comparison, WoS dates its origins to 1955, when Eugene Garfield created the initial Social Citation Index (Clarivate, 2020). Though much younger, Elsevier's Scopus data base 2004 origination was able to use the increases in available technology to quickly become a revered listing of expert-chosen journals (Elsevier, 2021).

In order to identify the countries that are in the region, the authors used the specification adapted by the Journal of Eastern European and Central Asian Research (JEECAR). Business journals in these countries that are listed in the comprehensive online version of Publishing Opportunities in Economic and Finance, which is commonly referred to as Cabell's, serve as the potential universe from which Eastern European journals were taken. This process permitted use of journal demographic information provided by Cabell's. Impact measures for these journals, as of late 2020, were obtained from Scopus.

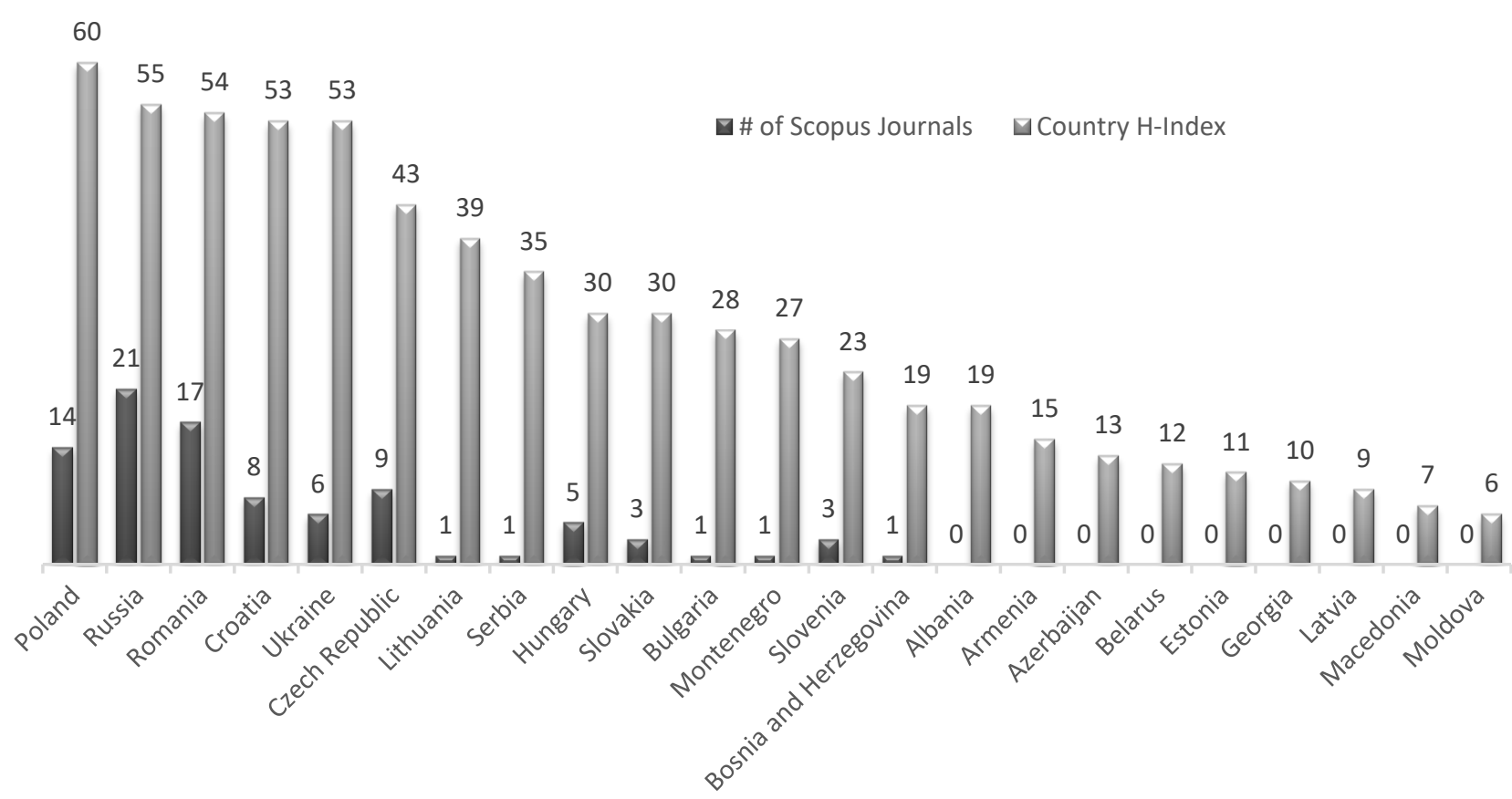

Figure 1: Central and Eastern European Economics and Finance Journals indexed in Scopus Source: Developed by authors based on SJR report of Scopus data from April 2020

None of the journals in Cabell's Directory of Publishing Opportunities in Economics and Finance and in Scopus are from the five countries in Central Asia that are part of the focus of the Journal of Eastern European and Central Asia Research. Hence, this study is one of the impacts of CEE journals in the economics and finance arena. According to Figure 1, a sufficient number of economics and finance journals are published in Poland and Romania to permit analysis of the impact of journals published in these nations separately, those from other CEE countries, and the region overall. Of course, this research is examining only a small fraction of the almost 3000 scientific journals published in Poland, 231 of which are indexed in Web of Science and 350 indexed in Scopus. Of Scopus' 350 journals, 88 are included in the Emerging Sources Citation Index, which is where one will also find the Journal of Eastern European and Central Asian 
Research. Although the Russian Federation has the highest number of economics and finance titles in Scopus (21) (and a second-highest $\mathrm{H}$ Index of 55), most of their journals are published in Russian language. A related issue highlighted by Chawla (2020) is that plagiarism resulted in 800 papers being removed from Russian journals in 2020. In addition, $76 \%$ of Russian citations are self-citations, which greatly diminishes the value of published articles. By comparison, the selfcitation rate in Poland and Romania is $37 \%$ and $27 \%$, respectively.

The remainder of this report has four components. First, a literature review focuses on impact factors. Second, the data discussion shares insights on the distribution of journals in Eastern Europe across WoS, Scopus, and Cabell's. Third, findings disclose useful information regarding Scopus ratings, journal demographics, and the journal review process. Results compare the two countries with the most economics and finance journals in the sample (i.e., Poland and Romania) to the remainder of East and Central Europe. Scopus statistics, journal characteristics, and review procedures of E\&F journals published in the region are compared to $\mathrm{E} \& \mathrm{~F}$ journals concerning CEE that are published outside the region. Finally, there is a conclusion with suggestions for future research.

\section{LITERATURE REVIEW}

\section{The Importance of Research Quality in Faculty Assessment}

Perhaps the most challenging issue faced by promotion and tenure committees is the evaluation of a candidate's research. The quality of the journals in which the candidate is publishing is frequently used as an indicator of the long-term impact of the candidate's research. Examples of this attribution of finance journal impact to candidate research can be found in Brogaard, Engelberg, and Van Wesep (2018) and Netter, Poulsen, and Kieser (2018).

Even after making the heroic assumption that journal quality can be used as a surrogate for research quality, several issues need to be resolved. A variety of measures have been used, over time, to assess the quality of journals. A popular measure of journal quality has been whether peers review submissions, and whether the journal follows a blind review style (Crane, 1967; Blank, 1991). Double-blind reviews, wherein the identity of both the author and reviewer are unknown to the other party are typically perceived to provide greater quality. In a comparison of the single-blind and doubleblind review process, Snodgrass (2007) found that when a double-blind review process was used acceptance rates were lower and referees turned in reviews that are more critical. However, using the broad-brush requirement that an article be in a peer-reviewed journal essentially created only two classes of articles and said little about the relative quality differences of journals. Although blind review was replaced by acceptance rates as a means to compare journal quality, concerns regarding editor manipulation of acceptance rates to influence journal submission rates has been and continues to be a concern (Ausloos, Nedic, and Dekanski, (2019)).

\section{Journal Databases}

What is impact? Are there a variety of impacts, such as one in the business world and one in the realm of scholarship itself? The frequently discussed gap between research and practice has been a concern of business schools, in terms of their legitimacy in the eyes of students, employers, and political entities (St (Kieser and Leiner, 2009) Johnson and Orr (2020)). Birkinshaw, Lecuona, and Barwise (2016) found that academic papers that are cited in bridge journals such as Sloan Management Review and finance's Practical Applications tend to have a high academic impact factor. A variety of alternative impact measures have been created, each of which attempts to gauge the relative importance of a journal.

Eugene Garfield (2006) devised the initial impact factor, with data published yearly since 1975 in the Journal Citation Reports (JCR) and now available from Clarivate Analytics. The SCImago Journal Rank (SJR) is another measure of the scholarly value of journal articles based on perceived journal quality. Journal quality is defined by SJR in terms of both the number of citations and the prestige of the journals in which a given journal's articles are cited. One essentially ends up with a measure of the average prestige per article for each Scopus 
journal. In a ranking of 300 economics journals, Moosa reports that the Journal of Finance moves up one notch if one uses this "prestige articles in prestige journals" measure (Moosa, 2017). Meanwhile, Currie and Pandher (2020) demonstrate a means to enhance the JCR and SJR ratings using a survey of active researchers.

The research presented here ties in most closely with that of Martin-Martin et al. (2018), who contrast WoS, Scopus, and Google Scholar databases. Across 2,500 highly cited documents across 252 subject categories, they found Google Scholar to have a higher proportion of the journals not found in the other two databases. In the Business, Economics, and Management domain, 61.4 percent of the journals were only located in Google Scholar, 2.3 percent were unique to Scopus, and 1.1 percent were unique to WoS. The highest overlap was 8.6 percent for Google Scholar and Scopus, dropping to 1.9 percent between Google Scholar and WoS, while only 0.7 percent were in Scopus and WoS without being in Google Scholar. That left 24.0 percent to be in all three databases. In a subsequent discussion, Martin-Margin et al. (2019) reveal that most of the difference arises from Google Scholar's willingness to include non-journal publications and non-English publications.

Detailed comparisons of Scopus and WOS exist in multiple economics areas. A mapping of the credit union literature by Maia el al. (2019), finds a large overlap between Scopus and WOS. While there is a large overlap, Scopus included over 102 additional unique articles, which was 21.0 percent of the 485 articles studied. In terms of geography, Capobianco-Uriarte et al. (2019)'s bibliometric analysis of international competitiveness, using Scopus, notes the economic research being done in Croatia, Slovenia, and Hungary, as well as a morass of nations simply referred to as "Eastern Europe." Through a worldwide Scopus analysis, comparing the United States, Eurasia, and India, Salmeron-Manzano and Manzano-Agugliaro (2017) find that "labor market" and "employment" has replaced "trade unions," "industrial relations," and "personnel' as key terms. They also note that excluding the United States, Eurasian journals are the most likely to include geographical terms in their keywords.
Although there tends to be biases in favor of the United States and journals in English, Scopus covers over $212 \%$ more journals than its nearest competitor in underrepresented nations, according to Tennant (2020), a tendency that has been recognized for over a decade (i.e., Aghaei Chadegani et al., 2013). Therefore, in addition to comparing journal demographics across geographic regions, an analysis is made of variation in Scopus metrics.

\section{Journal Impact Factors}

A significant amount of research attempts to identify the best bibliographic measures to identify journal quality. In an expansive study, Mingers and Yang (2017) contrast JCR, SRJ, and SNIP ratings of 37 business journals including four finance journals and two information systems journals. In the information systems discipline, Lowry et al. (2013) contrast expert opinion and bibliographic measures, finding a high degree of agreement in terms of journal quality. While some researchers (i.e., Merigo et al. (2015)) study a single journal's bibliometric measures across extended periods, our focus is one of analyzing and contrasting the current environment in which finance scholars, and especially economic researchers in Eastern Europe, find themselves.

Perhaps the most relevant set of prior research is the analyses of acceptance rates in finance, information systems, and other areas conducted by Krueger and Shorter. In their initial study, Krueger and Shorter (2012) investigated variation in acceptance rates over time in the finance and information systems journals. To test the robustness of these findings, acceptance rate variations across time and national boundaries were examined for journals in the accounting discipline (Krueger, Shorter, and Huff, 2012) and the marketing discipline (Shorter, Krueger, and Chatelain-Jardon, 2012). Instead of treating all journals in finance equally, the next analysis considered acceptance rates across seven finance sub-disciplines, such as insurance, real estate, and corporate finance, which found significant variations across finance sub-disciplines (Krueger, 2013). Meanwhile, Shorter (2013) took a more careful look at the impact of time to review, manuscript length, and how journal sponsorship impacts information 
system journal acceptance rates. Management journals were added to the investigation stream by Krueger (2014), which documented the relative impact of publication fees on acceptance rates. This report is a natural outgrowth of these research streams, because it investigates the analysis of various Scopus measures across the economics and finance journals published in or about CEE.

The issue of journal quality frequently is simplified to the requirement that a publication be included on a predetermined list of premier journals that is relevant to the discipline. For instance, Krueger (2017) compares journals included in the Chartered Association of Business Schools' Academic Journal Guide (AJG) (2015) and Australian Business Deans Council's (ABDC) Journal Quality List to the journals included in Cabell's Directory of Publishing Opportunities in Economics and Finance. One precursor to this research is the comparison of bibliometric measures and journal characteristics by Krueger and Lelkes (2019), which was expanded to a comparison of the United States, United Kingdom and the remainder of the world (Krueger, Lelkes, and Shorter (2020)) and presented at the 2020 Journal of Eastern European and Central Asian Research workshop. That study utilized the Journal Citation Reports (JCR), SCImago Journal Rank (SJR) (which was recast recently as the "Scholarly" Journal Rank), and Source Normalized Impact per Page (SNIP) citation-based quality measures. Accounting journals tended to be older, have higher acceptance rates, fewer issues, fewer referees, and shorter initial reviews. JCR measures were virtually identical, finance journal SJR ratings are higher, and accounting journal SNIP scores are higher.

A variation of the above research is to start with highly regarded journals and see how a variety of metrics including a.) SJR, b.) SNIP, and c.) Percentage of articles cite vary across discipline (Krueger and Shorter 2019). For instance, SJR measures for finance and management science journals are consistently higher than information systems journals, though the SJR value of any individual journal can be quite volatile (Krueger, Shorter, Colvin, 2021). This research extends the past research to the in-depth study of CEE.

\section{DATA ANALYSIS}

\section{Journal Database Comparison}

Capturing the sample of reputable E\&F journals is a critical step in the process of assessing the impact of research published in CEE. A related critical step is the identification of the list of countries in CEE. Fortunately, WoS and Scopus have an identical listing of Eastern European countries. Cabell's JournalAnalytics program allows one to sort journals by country. Journals from the countries on the WoS/Scopus listing were filtered from all journals found in Cabell's and aggregated with those found on either the WoS or Scopus listing. Instances of journals listed on two or three of these databases were determined.

As shown in the top row of Table 1, $237 \mathrm{E} \& \mathrm{~F}$ journals published in CEE are listed on at least one of these databases. Approximately, 86 percent of the journals are included only in one database, with 61 percent of the 237 total only being included in Cabell's. Twenty-four journals, which is just slightly over ten percent of the journals listed in the three databases, are found in two databases. This leaves the remaining 3 percent found in all three databases.

Figure 2 presents a pairwise illustration of the journal databases. Panel A shows that 79 percent of the journals found in WoS and Scopus, are located only in Scopus. Panel B shows that 98 percent of the journals found in WoS and Cabell's, are located only in Cabell's. Panel C shows that 68 percent of the journals found in Scopus and Cabell's are located in Cabell's alone, with another 28 percent being only in Scopus, leaving 4 percent to be in both databases. 
Table 1: Distribution of Eastern and Central European Economics and Finance Journals Across Analyzed Journal Databases

\begin{tabular}{|c|c|c|c|c|c|c|c|c|}
\hline \multirow[b]{2}{*}{ Country } & \multirow[b]{2}{*}{ Aggregate } & \multicolumn{3}{|c|}{$\begin{array}{c}\text { Frequency of Journals } \\
\text { Appearing in One } \\
\text { Database } \\
\text { (Subtotal: 205) }\end{array}$} & \multicolumn{3}{|c|}{$\begin{array}{c}\text { Combination of Three } \\
\text { Databases }\end{array}$} & \multirow{2}{*}{$\begin{array}{c}\text { Frequency } \\
\text { of Journals } \\
\text { Appearing } \\
\text { in all Three } \\
\text { Databases }\end{array}$} \\
\hline & & WoS & Scopus & Cabell's & $\begin{array}{l}\text { WoS \& } \\
\text { Scopus }\end{array}$ & \begin{tabular}{|l|} 
WoS \& \\
Cabell's
\end{tabular} & $\begin{array}{l}\text { Scopus \& } \\
\text { Cabell's }\end{array}$ & \\
\hline \multicolumn{9}{|c|}{ Panel A. Total Sample } \\
\hline All Nations & 237 & 1 & 60 & 144 & 15 & 1 & 8 & 8 \\
\hline $\begin{array}{l}\text { Percent of } \\
\text { sample }\end{array}$ & $100 \%$ & $0.4 \%$ & $25.3 \%$ & $60.8 \%$ & $6.3 \%$ & $0.4 \%$ & $3.4 \%$ & $3.4 \%$ \\
\hline \multicolumn{9}{|c|}{ Panel B. County Distribution } \\
\hline $\begin{array}{l}\text { Bosnia \& } \\
\text { Herzegovina }\end{array}$ & 3 & 0 & 0 & 2 & 0 & 0 & 0 & 1 \\
\hline Bulgaria & 1 & 0 & 1 & 0 & 0 & 0 & 0 & 0 \\
\hline Croatia & 17 & 0 & 3 & 9 & 4 & 0 & 1 & 0 \\
\hline $\begin{array}{l}\text { Czech } \\
\text { Republic }\end{array}$ & 28 & 0 & 5 & 19 & 1 & 0 & 1 & 2 \\
\hline Estonia & 2 & 0 & 0 & 2 & 0 & 0 & 0 & 0 \\
\hline Hungary & 10 & 0 & 2 & 5 & 1 & 0 & 2 & 0 \\
\hline Latvia & 5 & 0 & 0 & 5 & 0 & 0 & 0 & 0 \\
\hline Lithuania & 9 & 1 & 1 & 7 & 0 & 0 & 0 & 0 \\
\hline Montenegro & 1 & 0 & 0 & 0 & 1 & 0 & 0 & 0 \\
\hline Poland & 42 & 0 & 8 & 28 & 2 & 0 & 1 & 3 \\
\hline Romania & 59 & 0 & 11 & 42 & 2 & 0 & 2 & 2 \\
\hline $\begin{array}{l}\text { Russian } \\
\text { Federation }\end{array}$ & 24 & 0 & 18 & 3 & 3 & 0 & 0 & 0 \\
\hline Serbia & 8 & 0 & 1 & 6 & 0 & 1 & 0 & 0 \\
\hline Slovakia & 7 & 0 & 3 & 4 & 0 & 0 & 0 & 0 \\
\hline Slovenia & 10 & 0 & 2 & 7 & 0 & 0 & 1 & 0 \\
\hline Ukraine & 11 & 0 & 5 & 5 & 1 & 0 & 0 & 0 \\
\hline
\end{tabular}

Source: Developed by authors based on SCImago Journal \& Country Rank 2019 report and online Cabell's directory using Journalanalytics feature found at http://www2.cabells.com/about-journalytics.

At least one E\&F journal listed in at least one of these three databases is published in sixteen CEE countries, as shown in the first column of Panel B in Table 1. Romania and Poland have $59 \mathrm{E \& F}$ journals and $42 \mathrm{E} \& \mathrm{~F}$ journals, respectively, in these databases. The Czech Republic (with 28 E\&F journals), Russian Federation (with 24 E\&F journals), and Croatia (with 17 E\&F journals) round out the top five. Lithuania is the home to the lone WoS journal not included in the other databases. E\&F journals listed only in the Scopus database is characteristic of those published in the Russian Federation.
Among nations with at least ten journals, the highest proportion is located in Romania. Out of its $59 \mathrm{E} \& \mathrm{~F}$ journals, 71 percent are listed only in Cabell's. The highest overlap between WoS and Scopus occurs in Croatia and the Russian Federation. While the highest overlap between Scopus and Cabell's occurs in Hungary and Romania. Poland can boast three E\&F journals that are listed in all three databases. 
Panel A. Journals found in Web of Science and Scopus

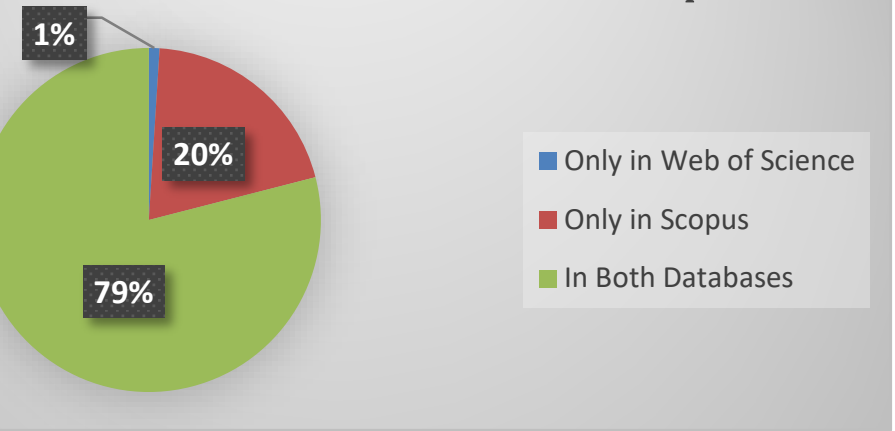

Panel B. Journals found in Web of Science and Cabell's
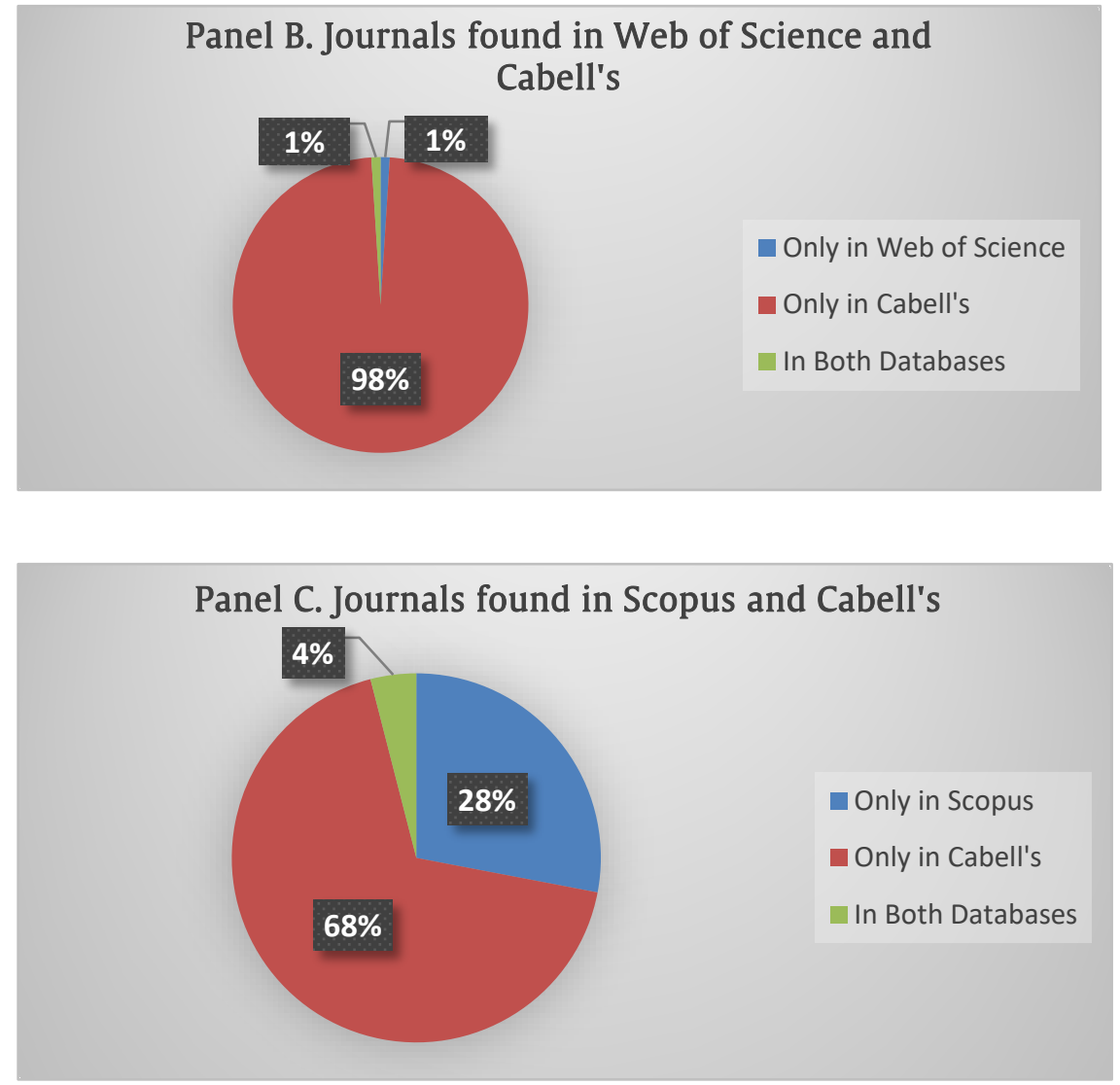

Figure 1: Pairwise Distribution of Economics and Finance Journals Published in Central and Eastern European Across Databases

Sources: Developed by authors based on SCImago, (n.d.). and Cabell's Scholarly Analytics, (n.d.)

\section{Research Database}

The focus of this research is the Scopus rankings, journal characteristics, and review procedure of $\mathrm{E} \& \mathrm{~F}$ journals published in CEE. Journal demographics are obtained from the online version of Cabell's Directory of Publishing Opportunities in Economics and Finance. As shown above, there are relatively few journals in both Scopus and Cabell's. In order to expand the sample set, the authors began with the listing of journals ascribed to each CEE country by Cabell's. 
SCImago website presence was determined for these journals. This procedure expands the number of E\&F journals with impact factor scores, which is consistent with the findings of Walters (2017). The process increases the number of CEE journals in the subsample with impact factor information from 16 (Some of two right columns in Panel A Table 1) to 32 (center value of Panel $A$ in Table 2). As shown in the second row of Table 2's Panel A, even with the expansion of the sample of journals for which impact factors are obtainable, the portion of journals for which impact factors are available amounts to only 23 percent of the $139 \mathrm{E} \& \mathrm{~F}$ journals in Cabell's which Cabell's positions in CEE. Given the limited sample size, generalizations made from this research to $E \& F$ research in CEE must be done with caution.
As with Table 1 , the CEE country distribution for the journals in the sample is given in Panel B of Table 2. Twelve journals are published in Romania, with another seven in Poland. That leaves 13 journals to represent the remainder of CEE. In percentage terms, 23 percent of the total sample is published in Poland, 33 percent in Romania, with the remaining 44 percent published elsewhere in CEE. Within the sample of journals for which SCImago reports impact factors, 22 percent are published in Poland, 37 percent are published in Romania and the remaining 41 percent are published elsewhere in CEE. Given the limited sample size, generalizations to all E\&F research in a given country have to be done with caution.

Table 2: Research Sample Distribution of Eastern and Central European Economics and Finance Journals listed in Cabell's and SCImago database

\begin{tabular}{|c|c|c|c|}
\hline & Cabell's Assignment & $\begin{array}{c}\text { Also in SCImago } \\
\text { Database }\end{array}$ & $\begin{array}{c}\text { Only in Cabell's } \\
\text { Total }\end{array}$ \\
\hline \multicolumn{4}{|c|}{ Panel A. Aggregated Distribution } \\
\hline All Nations & 139 & 32 & 107 \\
\hline Percent of Sample & $100 \%$ & $23 \%$ & $77 \%$ \\
\hline \multicolumn{4}{|c|}{ Panel B. National Distribution } \\
\hline Bosnia and Herzegovina & 3 & 0 & 3 \\
\hline Croatia & 10 & 2 & 8 \\
\hline Estonia & 2 & 0 & 2 \\
\hline Hungary & 7 & 42 & 3 \\
\hline Latvia & 5 & 1 & 4 \\
\hline Lithuania & 7 & 1 & 6 \\
\hline Poland & 32 & 7 & 25 \\
\hline Romania & 46 & 12 & 34 \\
\hline Russian Federation & 3 & 0 & 3 \\
\hline Slovakia & 7 & 2 & 5 \\
\hline Serbia & 4 & 1 & 3 \\
\hline Slovenia & 8 & 1 & 7 \\
\hline Ukraine & 5 & 1 & 4 \\
\hline
\end{tabular}

Source: Developed by authors based on SCImago, (n.d.). and Cabell's Scholarly Analytics, (n.d.)

NOTE: Eight Eastern European countries (Albania, Armenia, Azerbaijan, Belarus, Bulgaria, Georgia, Moldova, Montenegro, Northern Macedonia) and all five Central Asian countries (Kazakhstan, Kyrgyzstan, Tajikistan, Turkmenistan, Uzbekistan) identified as being JEECAR's focus do not have any journals listed in Cabell's directory.

In order to create a benchmark for these journals, journals about finance conditions in this region published externally to the region were located. An example of these journals is 
Journal of Eastern European and Central Asian Research (JEECAR), which is published in the United States. A listing of these journals is given below.

External Published Journals including Eastern Europe and Central Asia (Nation of Publication):

- Eastern European Economics (United States)

- Eastern European Politics (United Kingdom)

- Europe-Asia Studies (formally Soviet Union Studies) (United Kingdom)

- Eurasia Business Review(Turkey)

- Asian Business \& Management (Germany)

- Asia European Journal(Singapore)

- Journal of Eastern Europe and Central Asian Research(United States)

\section{FINDINGS}

Analysis of Eastern European Economics and Finance Journal Impact across Nations

CiteScore. CiteScore is the average number of citations that an article has received over a threeyear period. As shown in the right column of Table 3's Panel A, the average CEE journal article in this sample has 1.10 citations, with a range from 0.10 to 4.3. The highest median score is found in Other CEE Countries, while the Romanian journals have the lowest CiteScores. These observations for Romanian journals are true whether one considers the maximum or minimum number of average citations per article.

CiteScore Ranking within Discipline. Given differences in the number of citations across disciplines, it is critical to adjust the CiteScore measure for the level of citation in the E\&F discipline. A value of 1.0 would indicate the journal is the most cited journal in its discipline. As exhibited in Panel B of Table 2, the Polish journals have an average ranking that is slightly above the E\&F journal mean and median, Romanian journals are lower, and Other CEE Journals have a rating that is right at the median for all E\&F journals. Overall, Eastern European journals are quite well received, with a median and mean of 53, and a range from the top 91\% (in Poland) to a much lower $11 \%$ (in Romania).

Percentage of Articles Cited. Of course, the citations may be to a single article. Hence, Panel $C$ of Table 3 presents information on the percentage of articles cited. For instance, the typical, median Polish journal has $46.0 \%$ of its articles cited, with a range of $32 \%$ to $69 \%$. Articles in Romanian journals are less likely to be cited, with a median of $31.5 \%$. In one Romanian journal included in the SCImago database, only 11 percent of the articles are cited. E\&F Journals outside these two countries tend to have a higher percentage of articles cited in subsequent research, whether one is considering the mean, median, maximum, or minimum.

SJR. The Scientific Journal Ranking (SJR), which considers both the number of citations and the prestige of the journals in which the research is cited, is reported in Panel D of Table 3. Looking at the right column, one can see that the SJR range for CEE journals in the sample runs from 0.047 to 1.771 , with a similar mean and median of approximately 0.7. Romanian E\&F journals tend to be on the low side of these benchmarks, while Polish journals are closest to the average. That leaves journals not in these countries as those having the highest SJR values in the region.

SNIP. The Source Normalized Impact per Paper (SNIP) metric adjusts the SJR value for citation tendencies in the discipline. It is akin to the CiteScore rating within discipline adjustment for the raw CiteScore, however it is possible to have SNIP values above 1.0. As shown in the right column of Panel E in Table 3. E\&F journals published in CEE have SNIP values ranging from 0.112 to 1.185 , with a median of 0.276 . Consistent with the information above, Romanian SNIP values are below average, while Polish journals have typical readings for the region. 
Table 3: CEE Journal Impact

\begin{tabular}{|c|c|c|c|c|}
\hline & $\begin{array}{c}\text { Polish } \\
\text { Journals }\end{array}$ & $\begin{array}{l}\text { Romanian } \\
\text { Journals }\end{array}$ & $\begin{array}{l}\text { Other CEE } \\
\text { Journals }\end{array}$ & All Journals \\
\hline \multicolumn{5}{|c|}{ Panel A. CiteScore } \\
\hline Mean & 1.51 & 1.06 & 2.75 & 1.51 \\
\hline Median & 1.00 & 0.55 & 1.90 & 1.10 \\
\hline Maximum & 3.10 & 2.70 & 4.30 & 4.30 \\
\hline Minimum & 0.60 & 0.10 & 0.40 & 0.10 \\
\hline \multicolumn{5}{|c|}{ Panel B. CiteScore Ranking within discipline $(100=$ best $)$} \\
\hline Mean & 57.0 & 43.5 & 56.4 & 53 \\
\hline Median & 57 & 42 & 50 & 53 \\
\hline Maximum & 91 & 84 & 87 & 91 \\
\hline Minimum & 34 & 11 & 12 & 11 \\
\hline \multicolumn{5}{|c|}{ Panel C. Percentage of Article Cited } \\
\hline Mean & 50.1 & 32.7 & 53.8 & 45.3 \\
\hline Median & 46.0 & 31.5 & 54.0 & 48.0 \\
\hline Maximum & 69.0 & 56.0 & 72.0 & 72.0 \\
\hline Minimum & 32.0 & 11.0 & 22.0 & 11.0 \\
\hline \multicolumn{5}{|c|}{ Panel D. SJR } \\
\hline Mean & 0.740 & 0.511 & 0.856 & 0.738 \\
\hline Median & 0.719 & 0.371 & 0.886 & 0.704 \\
\hline Maximum & 1.374 & 1.488 & 1.771 & 1.771 \\
\hline Minimum & 0.570 & 0.047 & 0.084 & 0.047 \\
\hline \multicolumn{5}{|l|}{ SNIP } \\
\hline Mean & 0.349 & 0.256 & 0.406 & 0.363 \\
\hline Median & 0.275 & 0.147 & 0.302 & 0.276 \\
\hline Maximum & 0.707 & 0.720 & 1.185 & 1.185 \\
\hline Minimum & 0.184 & 0.112 & 0.117 & 0.112 \\
\hline
\end{tabular}

Source: Developed by authors based on SCImago, (n.d.). and Cabells Scholarly Analytics, (n.d.)

Analysis of Eastern European Economics and Finance Journal Characteristics

Following are the characteristics of $\mathrm{E} \& \mathrm{~F}$ journals published in CEE:

Launch. Finding differences in the impact of journals published in Poland, Romania, and the remainder CEE, the next step was to assess whether these differences were due to variation in either the journals or their review processes. Table 4 exhibits a variety of journal characteristics, while Table 5 focuses on a variety of review process characteristics. In order to keep the focus on impact factors, Table 4 and Table 5 are based on the sample of CEE journals for which SCImago provides statistics. The typical (i.e., median) E\&F journal published in CEE, in this sample, is less than two decades old. The median launch date is 2004 , with a range from 1973 to 2017, as displayed in the right column of Table 4's Panel A. Polish journals tend to have the most recent launch dates, while Romanian journals are newer than those found in other CEE countries.

Frequency of issue. The typical number of issues per year in CEE is 4, with a range from 1 to 12 , as shown in Panel B of Table 4. Due to the commonality of journals with less than 4.0 issues per year, the mean frequency in the region is 3.3. 
Polish E\&F journals included in the sample tend to have more issues per year, with Romanian journals having the fewest issues per year.

Table 4: Characteristics of East European Journal Journals in SCOPUS

\begin{tabular}{|c|c|c|c|c|}
\hline & $\begin{array}{c}\text { Polish } \\
\text { Journals }\end{array}$ & $\begin{array}{l}\text { Romanian } \\
\text { Journals }\end{array}$ & $\begin{array}{c}\text { Other Eastern } \\
\text { European Journals }\end{array}$ & $\begin{array}{c}\text { All Eastern } \\
\text { European } \\
\text { Journals }\end{array}$ \\
\hline \multicolumn{5}{|c|}{ Panel A. Launch (Year) } \\
\hline Mean & 2009.9 & 2002.3 & 1997.2 & 2001 \\
\hline Median & 2012 & 2000.5 & 1997 & 2004 \\
\hline Earliest & 1993 & 1990 & 1973 & 1973 \\
\hline Most recent & 2017 & 2012 & 2017 & 2017 \\
\hline \multicolumn{5}{|c|}{ Panel B. Frequency (Issues per year) } \\
\hline Mean & 4.4 & 2.8 & 3.2 & 3.3 \\
\hline Median & 4 & 2.5 & 2 & 4 \\
\hline Fewest & 1 & 1 & 2 & 1 \\
\hline Most & 12 & 5 & 4 & 12 \\
\hline \multicolumn{5}{|c|}{ Panel C. Maximum Length (pages) } \\
\hline Mean & 24.9 & 20.8 & 20.2 & 21.4 \\
\hline Median & 24 & 20 & 18 & 20 \\
\hline Shortest & 12 & 10 & 8 & 8 \\
\hline Longest & 50 & 30 & 55 & 55 \\
\hline \multicolumn{5}{|c|}{ Panel D. Invited Articles (Percent of all articles) } \\
\hline Mean & 5.1 & 14.2 & 5.8 & 8.5 \\
\hline Median & 2.5 & 5.2 & 2.5 & 2.5 \\
\hline Lowest & 0 & 7.5 & 0 & 0 \\
\hline Highest & 29.5 & 80.5 & 25.5 & 80.5 \\
\hline
\end{tabular}

Source: Developed by authors based on SCImago, (n.d.). and Cabell's Scholarly Analytics, (n.d.)

Maximum Length. The maximum target length of articles is approximately 20 pages in this sample, with a median of 20 and a mean of 21.4. In instances where journals stated a maximum number of words or characters, page length conversions were based upon guidelines provided by the American Association of Individual Investors (AAII, 2018), as collaborated by Smith (2020) and Dexter (2021). Maximum lengths range from 8 to 55 pages. Polish journals tend to be longer, as reported in the first column of Table 4's Panel C.

Percentage of Invited Articles. Another journal characteristic that varies greatly among journals is the percentage of articles that are invited. As shown in the right columns of Panel $\mathrm{D}$ in Table 4, from zero to 80.5 percent of articles in individual journals are invited. A median of only 2.5 percent, suggests that having an 80.5 percent invited percentage is abnormally high. Romanian E\&F journals, in the sample, tend to have the highest proportion of articles that are invited.

\section{Review Process Characteristics of E\&F Journals Published in CEE}

Acceptance Rate. As shown in Table 5's Panel A, acceptance rates range from 5 to 90 percent, with an average of 50 among E\&F journals published in CEE. A mean below the median suggest that the 90 percent is more of an outlier than the 5 percent acceptance rate. Polish E\&F journals, in the sample, have the highest median acceptance rate, at 59 percent. Romanian journals had the highest mean acceptance rate, 
of 52.3 percent. Acceptance rates in other CEE countries range from 5 percent to 83 percent.

Reviewers. As shown in Table 5's Panel B, the median number of reviewers at E\&F journals published in CEE is 3. Given that the average is below 3, at 2.7, there seems to be a greater likelihood that there will be 2 reviewers (the minimum for this sample) instead of 4 reviewers (the maximum. There typically are more reviewers at Polish journals; however, the maximum is 3 reviewers.

Review Time. As shown in the Table 3's Panel C, review times are approximately 2.5 months, with a range from 1.5 to 4.5 months. The longest anticipated review times are encountered with Polish journals, while they are shorter at Romanian journals. In fact, none of the Romanian journals has an anticipated review time in excess of 2.5 months.

Time to Publication. On average, it takes 5.4 months for an accepted E\&F article to be published in CEE. While some journals take up to 10.5 months, other include accepted articles in their publication within a month. The time between acceptance and publication is the longest in Poland, with a slightly below average wait for Romanian journals.

Table 5: CEE Journal Review Process Characteristic

\begin{tabular}{|c|c|c|c|c|}
\hline & $\begin{array}{c}\text { Polish } \\
\text { Journals }\end{array}$ & $\begin{array}{l}\text { Romanian } \\
\text { Journals }\end{array}$ & $\begin{array}{c}\text { Other Eastern } \\
\text { European } \\
\text { Journals } \\
\end{array}$ & $\begin{array}{c}\text { All Eastern } \\
\text { European } \\
\text { Journals }\end{array}$ \\
\hline \multicolumn{5}{|c|}{ Panel A. Acceptance Rate (Percent of articles submitted) } \\
\hline Mean & 50.7 & 52.3 & 37.8 & 46.2 \\
\hline Median & 59.0 & 55.2 & 29.0 & 50.0 \\
\hline Maximum & 90.5 & 75.0 & 83.0 & 90.0 \\
\hline Minimum & 20.0 & 25.0 & 5.0 & 5.0 \\
\hline \multicolumn{5}{|c|}{ Panel B. Reviewers (Both internal and external) } \\
\hline Mean & 2.9 & 2.7 & 2.6 & 2.7 \\
\hline Median & 3 & 2.5 & 2.5 & 3 \\
\hline Maximum & 3 & 4 & 4 & 4 \\
\hline Minimum & 2 & 2 & 2 & 2 \\
\hline \multicolumn{5}{|c|}{ Panel C. Review Time (months) } \\
\hline Mean & 4.1 & 2.2 & 2.4 & 2.6 \\
\hline Median & 4.5 & 2.5 & 2.5 & 2.5 \\
\hline Maximum & 4.5 & 2.5 & 4.5 & 4.5 \\
\hline Minimum & 2.5 & 1.5 & 1.5 & 1.5 \\
\hline \multicolumn{5}{|c|}{ Panel D. Time to Publication (months) } \\
\hline Mean & 7.5 & 4.8 & 5.2 & 5.4 \\
\hline Median & 7.5 & 4.5 & 4.5 & 4.5 \\
\hline Maximum & 10.5 & 7.5 & 7.5 & 10.5 \\
\hline Minimum & 4.5 & 0.8 & 2.5 & 0.8 \\
\hline
\end{tabular}

Source: Developed by authors based on SCImago, (n.d.). and Cabell's Scholarly Analytics, (n.d.)

Comparison of Eastern European Finance and Economics Journals to Journals about the Region Published Elsewhere

Impact Statistics A logical question is one of whether there is a difference between the publications in a region and the publications about the region by outside parties. To answer this question, the authors located several journals published outside Eastern Europe about Eastern Europe, including the Journal of Eastern European and Central Asian Research. Since the primary focus is not on impact factors, the sample for this portion of the study was all CEE 
journals included in Cabell's, without a requirement that the journal also be listed in SCImago's listing. Hence, there are slight variation in the Table 6's CEE column and that reported in Table 4 and Table 5.

As exhibited in the first two columns of Table 6's Panel A, although CEE journals had a higher maximum CiteScore, they had a lower mean and median CiteScore value. The CiteScore percentile within the E\&F discipline is consistently higher for the foreign journals covering CEE. While the median CiteScore Percentile level of foreign journals is 68 percent, the median value of CEE journals in the sample is only 53 percent. Examining the center columns of Panel A in Table 6 , while the median percentage of CEE-published article cited is 48 percent, journals published about CEE from outside the region had a higher 60 percent likelihood of being cited.

As shown in the SJR columns of Table 6's Panel $A$, the most impactful journal published in Eastern Europe is 74 percent (i.e., (1.18$0.68) / 0.68$ - 1) more impactful than the most impactful external journal about the region. Nonetheless, the mean and median SJR values suggest that the foreign journals are 22 percent (i.e., $(0.44-0.36) / 0.36-1)$ and 64 percent more impactful (i.e., $(0.46-0.28) / 0 / 28)$ than CEE journals. SNIP values are consistent with these findings, with foreign journals about the region being more impactful by a ratio of 1.0 to 0.7 .

Table 6: Comparison of Journals regarding East Europe and Central Asia Published In and Outside of the Region

\begin{tabular}{|c|c|c|c|c|c|c|c|c|c|c|c|c|}
\hline \multicolumn{13}{|c|}{ Panel A. SCOPUS Statistics } \\
\hline \multirow[b]{2}{*}{ Origin } & \multicolumn{2}{|c|}{ CiteScore } & \multicolumn{3}{|c|}{$\begin{array}{l}\text { CiteScore } \\
\text { Percentile in } \\
\text { Discipline }\end{array}$} & \multicolumn{2}{|c|}{$\begin{array}{l}\text { Percentage of } \\
\text { Articles Cited }\end{array}$} & \multicolumn{3}{|c|}{ SJR } & \multicolumn{2}{|r|}{ SNIP } \\
\hline & CEE & Foreign & \multicolumn{2}{|c|}{\begin{tabular}{|l|l|} 
CEE & \\
\end{tabular}} & Foreign & CEE & Foreign & CEE & \multicolumn{2}{|c|}{ Foreign } & CEE & Foreign \\
\hline Mean & 1.54 & 2.16 & \multicolumn{2}{|c|}{53.0} & 66.4 & 46.8 & 59.2 & 0.36 & \multicolumn{2}{|c|}{0.44} & 0.74 & 0.99 \\
\hline Median & 1.2 & 2.1 & \multicolumn{2}{|c|}{53} & 68 & 48 & 60 & 0.28 & \multicolumn{2}{|c|}{0.46} & 0.70 & 1.00 \\
\hline Maximum & 4.3 & 3.9 & \multicolumn{2}{|l|}{91} & 94 & 72 & 77 & 1.18 & \multicolumn{2}{|c|}{0.68} & 1.77 & 1.44 \\
\hline Minimum & 0.1 & 0.4 & \multicolumn{2}{|l|}{11} & 17 & 11 & 26 & 0.11 & \multicolumn{2}{|c|}{0.22} & 0.05 & 0.48 \\
\hline \multicolumn{13}{|c|}{ Panel B. Journal Characteristics } \\
\hline & \multicolumn{3}{|c|}{$\begin{array}{l}\text { Year of Launch } \\
\text { (In Print or } \\
\text { Electronic } \\
\text { Medium) }\end{array}$} & \multicolumn{3}{|c|}{$\begin{array}{l}\text { Publication } \\
\text { Frequency } \\
\text { (Each year) }\end{array}$} & \multicolumn{3}{|c|}{$\begin{array}{c}\text { Maximum } \\
\text { Manuscript Length } \\
\text { (pages) }\end{array}$} & \multicolumn{3}{|c|}{$\begin{array}{c}\text { Percentage of } \\
\text { Articles Invited }\end{array}$} \\
\hline Origin & CEE & Foreig & & CEE & & oreign & CEE & Forei & & $\mathrm{CEF}$ & & Foreign \\
\hline Mean & 2000.1 & 1991. & & 3.1 & & 0.1 & 19.0 & 23.5 & & 11. & & $7.4 \%$ \\
\hline Median & 2003 & 1995 & & 3 & 5 & & 16 & 22 & & 2.5 & & $2.5 \%$ \\
\hline Maximum & 1919 & 1949 & & 12 & 1 & 18 & 55 & 40 & & 80. & & $25.5 \%$ \\
\hline Minimum & 2017 & 2014 & & 1 & 2 & & 6 & 10 & & $0 \%$ & & $2.5 \%$ \\
\hline Panel C. F & ew cn & $11 \mathrm{dctensth}$ & & & & & & & & & & \\
\hline & $\begin{array}{r}\text { Acce }_{1} \\
(\mathrm{Pe}\end{array}$ & $\begin{array}{l}\text { tance Rat } \\
\text { centage) }\end{array}$ & & & & $\begin{array}{l}\text { r of } \\
\text { jers } \\
\text { al \& } \\
\text { ial) }\end{array}$ & $\begin{array}{r}\text { Time } \\
\text { Initial } \\
(\mathrm{N}\end{array}$ & $\begin{array}{l}\text { to Revie } \\
\text { Submiss } \\
\text { onths) }\end{array}$ & & & $\begin{array}{l}\text { ne to } \mathrm{F} \\
\text { fter } \mathrm{Ac}\end{array}$ & $\begin{array}{l}\text { ublication } \\
\text { ceptance) }\end{array}$ \\
\hline Origin & CEE & Foreig & & CEE & & oreign & CEE & Forei & & CEE & & Foreign \\
\hline Mean & $51.4 \%$ & $19.1 \%$ & & 2.87 & & 2.4 & 2.6 & 2.7 & & 5.6 & & 4.2 \\
\hline Median & $56.5 \%$ & $20.0 \%$ & & 2 & 3 & & 2.5 & 2.5 & & 4.5 & & 3.2 \\
\hline Maximum & $90 \%$ & $32 \%$ & & 7 & 3 & & 7 & 4.5 & & 13. & & 10.5 \\
\hline Minimum & $5 \%$ & $7 \%$ & & 1 & 1 & & \begin{tabular}{|l|}
0.3 \\
\end{tabular} & 1.5 & & 0.8 & & 2 \\
\hline
\end{tabular}

Source: Developed by authors based on SCImago, (n.d.). and Cabells Scholarly Analytics, (n.d.) 
Journal Characteristics Panel B of Table 6 parallels information provided in in Table 4 , by focusing on the journal's year of launch, publication frequency, maximum manuscript length, and percentage of invited articles. EEC journals are younger, have a less frequent publication frequency, are shorter, and have a similar percentage of invited articles. The median difference in age, is 8 years (i.e., 2003 1995). An additional two editions (i.e., 5 - 3) are typically published each year by foreign journals. E\&F journals published in CEE tend to be 37.5 percent longer (i.e., $(22-16) \div 16)$ ). For both the Eastern European Journals and journals about the region published outside the region, $2.5 \%$ of articles are typically invited as denoted by the median statistic.

Review Procedure Panel C of Table 6 parallel's information provided in in Table 5 , by focusing on the acceptance rates, number of reviewers, time to review, and time to publication. Acceptance rates are over twice as high for CEE journals, with a median acceptance rate that is almost three times as high. One reason may be the higher number of reviewers (i.e., 3 v. 2) utilized by foreign journals. Although the time to review is very similar, CEE journals use a much wider range of times to review the initial publication. Although some of the E\&F articles appear within a month, more time passes between acceptance and publication at CEE journals, where the median is 1.3 months (i.e., 4.5 - 3.2) longer.

\section{CONCLUSION}

Central and Eastern Europe (CEE) has experienced economic success during the past three decades. In academic circles, the question that arises is one of whether the impact of scholarly publication in the region has kept pace with this growth. In order to answer this question, the economics and finance (E\&F) journals published in CEE were studied on multiple dimensions. One plane concerns whether CEE journals have begun to be included in any of the leading databases listing quality journals. This research investigated the appearance CEE journals in the Web of Science, Scopus, and Cabell's databases. Much to the authors' surprise, many E\&F journals are not listed in Cabell's Directory of Publishing
Opportunities in Economics and Finance, which was historically viewed as the holy grail of journals in which up-and-coming researchers should publish! Nonetheless, a vast majority (61\%) of this study's 237 E\&F journals appear in Cabell's Directory but not in either Web of Science or Scopus. Approximately one quarter of the journals are published in Poland, with onethird published in Romania. Scopus-indexed journals account for approximately two out of every nine journals.

A second dimension on which CEE journals were evaluated is that of impact factors. Polish journals have higher CiteScore rankings when adjusted for discipline, with an average of 50 percent of articles cited. Romania tends to trail other areas in CEE based on both CiteScore (median of 0.55), percentage of article cited (i.e., 32 percent), as well as the prestige based SJR and SNIP impact factors.

Next, the analysis turned to journal demographics, including both journal characteristics and journal review processes. Polish journals tend to be younger, have more issues each year, a longer maximum length, and lower percent of articles invited. Poland and Romania have an acceptance rate that is higher than that found elsewhere in CEE. Overall, there was a lot of overlap in terms of the number of reviewers, initial review time, and time from acceptance to publication.

The final dimension of this research contrasted E\&F journals regarding CEE published outside CEE to those published in the region. CEE journals had a higher impact, whether using CiteScore, CiteScore within the discipline, percentage of articles cited or either of the impact measures base on prestige of the citing journal (i.e., SJR or SNIP). Journals about CEE that are published outside the area have a.) a longer history, b.) more issues per year, c.) a higher maximum page limit, and d.) lower percentage of invited articles. Meanwhile, in terms of review characteristics, they are much more selective and use a higher median number of reviewers. While external journals require a similar amount of time to make a decision, the publication occurs within a shorter timeframe.

This research can be advanced on several fronts. One would be to include the Web of Science's JCR impact value, h-index, or other 
measures of journal quality. Another would be to consider alternative business disciplines, such as marketing and management. Third, it would be possible to expand beyond business to consider the impact of CEE journals in nonbusiness areas. Fourth, over time it would be possible to identify trends in the impact of E\&F journals published in CEE. It is quite likely that like the CEE economy, scholars will find growth in the impact of journals published in Central and Eastern Europe.

\section{REFERENCES}

AAII Association (2018). Journal page limits and word count guidelines.

Aghaei Chadegani, A., Salehi, H., Yunus, M. M., Farhadi, H., Fooladi, M., Farhadi, M., and Ale Ebrahim, N, (2013). A Comparison between Two Main Academic Literature Collections: Web of Science and Scopus Databases (April 7, 2013). Asian Social Science, Vol. 9, No. 5, pp. 18-26, April 27, 2013, Available at SSRN: https://ssrn.com/abstract $=2257540$

Association of Business Schools (2015). Academic Journal Guide 2015. London: Chartered Association of Business Schools. Downloaded at www.associationofbusinessschools.org.

Ausloos, M., Nedic, O., and Dekanski, A. (2019). Correlation between submission and acceptance of papers in peer reviewed journals. Scientometrics, Vol. 2019, p. 279302.

https://link.springer.com/article/10.1007/s1 1192-019-03026-X.

Birkinshaw, J., Lecuona, R., and Barwise, P. (2916), The relevance gap in business school research: Which academic papers are cited in management bridge journals?, Academy of Management Learning \& Education, Vol. 15 No. 4, pp. 86-702, https://doi.org/10.5465/amle.2015.0282.

Brogaard, J., Engelberg, J., and Van Wesep, E. (2018), "Do economists swing for the fences after tenure?," Journal of Economic Perspectives, Vol. 32 No. 1, pp. 179-194.

Cabells (2021). About Us. [Internet]. Retrieved January 30, 2021, from https://www2.cabells.com/about.
Cabells Scholarly Analytics, (n.d.). Journalanalytics: Cabell's classification index [Internet]. Retrieved January 28, 2021, from http://www2.cabells.com/aboutjournalytics

Capobianco-Uriarte, M., Casado-Belmonte, M., Martin-Carrillo, G.M., and Teran-Yepez, E. (2019). A Bibliometric Analysis of International Competitiveness (1982-2017). Sustainability, 11(1877). http://dx.doi.org/10.3390/su 1107177.

Chawla, D.S. (2020). Russian journals retract more than 800 papers after 'bombshell' investigation. Science, January 6, 2020. https://www.sciencemag.org/news/2020/01 /russian-journals-retract-more-800-papersafter-bombshell-investigation.

Clarivate (2020). 2019 Annual Report. http://wokinfo.com/about/whoweare/.

Currie, R. R., and Pandher, G. S. (2020). Finance journal rankings: Active scholar assessment revisited. Journal of Banking \& Finance, 111, 105717.

Dexter, Allison (2021). How many words per page?, Blog. https://wordcounter.io/blog/how-manywords-per-page/.

Elsevier (2021). Expertly curated abstract \& citation database. https://www.elsevier.com/solutions/scopus.

Garfield, E. (2006), "The history and meaning of the journal impact factor," JAMA: The Journal of the American Medical Association, Vol. 295 No. 1, 90-93.

Johnson, S., and Orr, K. (2020). What is business school research for? Academic and stakeholder perspectives, politics and relationality. Studies in Higher Education, Vol. 45 No. 3, 557-578.

Krueger, T.M. (2013), “Acceptance rates of finance journals dedicated to various areas: Impact of review type and reviewer number," Mustang Journal of Accounting and Finance, Vol. 3, pp. 65-88.

Krueger, T.M. (2014), "Paying for Acceptance? A study of academic management journals," Mustang Journal of Business and Ethics, Vol. 6, pp. 31-47.

Krueger, T.M. (2017), “A comparison of CABS’ 
Academic Journal Guide, "Australian Business Deans Council's List, and Cabell's Directory of Publishing Opportunities in Finance. Journal of Financial Education, Vol. 43 No. 2, pp. 313-338.

Krueger, T.M. and Lelkes, A.M. (2019), "Bibliometric measures and journal characteristics of leading accounting and finance journals," Journal of Accounting and Finance, Vol. 19 No. 7, pp.87-101.

Krueger, T.M., Lelkes, A.M., and Shorter, J. (2020) "Nation-based differences in citation-based business journal quality measures and characteristics, Journal of Education for Business, pages 1-13. https://doi.org/10.1080/08832323.2020.174 9015.

Krueger, T.M., and Shorter, J. (2019), “A comparison of high-quality finance journal and high-quality information systems journals," Journal of Higher Education Theory and Practice, Vol. 19 No. 1, pp. 95104.

Krueger, T.M., and Shorter, J. (2012), "Variation in scholarly review processes and acceptance rates across time and disciplines," Southwestern Business Administration Journal, Vol. 11, pp. 71-112.

Krueger, T.M., Shorter, J. and Colvin, R. (2021). "Bibliographic Measures of Top-Tier Finance Information Systems, and Management Science Journals," Economic and Business Research, forthcoming.

Krueger, T.M., Shorter, J., and Huff, K. (2012),“International differences in business journal acceptance rates across business disciplines," International Journal of Business and Social Science, Vol. 3, pp. 1-16.

Kulczycki E, Rozkosz E.A. (2017), "Does an expert-based evaluation allow us to go beyond the Impact Factor? Experiences from building a ranking of national journals in Poland." Scientometrics. Vol. 111, No. 1, pp. 417-442. doi: 10.1007/s11192-0172261-x. Epub 2017 Feb 1. PMID: 28386153; PMCID: PMC5362673.

Lowry, P.B., Gaskin, J., Humphreys, S.L., Moody, G.D., Galletta, D.F., Barlow, J.B., and Wilson, D.W. (2013), "Evaluating journal quality and the Association for Information Systems
Senior Scholars' journal basket via bibliometric measures: Do expert journal assessments add value?" MIS Quarterly, Vol 37 No. 4, pp. 993-1012.

Maia, S.D., Benedicto, G. C., Prado, J.W., Robb, D.A., Bispo, O.N., and Britio, M. J. (2019). Mapping the literature on credit unions: $A$ bibliometric investigation grounded in Scopus and Web of Science. Scientometrics, 2019 (1), 929-960. https://doi.org/10.1007/s11192-019-031651.

Martín-Martín, A., Orduna-Malea, E., Thelwall, M., and Delgado López-Cózar, E. (2018). Google Scholar, Web of Science, and Scopus: A systematic comparison of citations in 252 subject categories. Journal of Informetrics, Vol. 12, No. 4 (2018), pp. 1160-1177. https://doi.org/10.1016/j.joi.2018.09.002.

Martin-Martin, A., Orduna-Malea, E., Thalwall, M., and Delgado-Lopez-Cozar, E. (2019). Google Scholar, Web of Science, and Scopus: Which is best for me? London School of Economics (December 3, 2019). Blog. https://blogs.lse.ac.uk/impactofsocialscience s/2019/12/03/google-scholar-web-ofscience-and-scopus-which-is-best-for-me/.

Merigó, J.M., Mas-Tur, A, Roig-Tierno, N., and Ribeiro-Soriano, D. (2015), “A bibliometric overview of the Journal of Business Research between 1973 and 2014, Journal of Business Research, Vol. 68 No. 12, pp. 2645-2653.

Mingers, J. and Yang, L. (2017), "Evaluating journal quality: A review of journal citation indicators and ranking in business and management," European Journal of Operational Research, Vol 257 No. 1, pp. 323-337.

Moosa, I.A. (2017)," Citations, journal ranking and multiple authorships: Evidence based on the top 300 papers in economics," Applied Economics Letters, Vol. 24 No. 3, pp. 175-181.

Netter, J.M., Poulsen, A.B., and Kieser, W.P. (2018), "What does it take? Comparisons of research standards for promotion in finance," Journal of Corporate Finance, Vol. 49, pp. 379-387.

Salmerón-Manzano, E., \& Manzano-Agugliaro, F. (2017). Worldwide scientific production 
indexed by Scopus on labour

relations. Publications, 5(4), 25.

http://dx.doi.org/10.3390/publications5040 02

SCImago, (n.d.). SJR - SCImago Journal \& Country Rank [Portal]. Retrieved January 28, 2021, from http://www.scimagojr.com

Shorter, J. (2013), " Distinctions in academic journal review processes and acceptance rates across time \& how time to review, manuscript length, and sponsorship effect periodical acceptance rates in the information systems disciplines," Journal of Information Systems Technology \& Planning, Vol. 5 No. 15, pp. 87-111.

Shorter, J, Krueger, T.M., and Chatelain-Jardon, R. (2012)," Discipline, nation, and timebased differences in business journal acceptance rates and review processes," Journal of International Business Management \& Research, Vol. 3, pp. 147163.

Smith, H. (2020). Character limits to estimated page and word counts. T Foundant Technologies blog. https://foundant.helpjuice.com/77470forms/229310-how-many-pages-is-10-000characters\#character-limits-into-estimatedword-and-page-counts.

Tennant, J. (2020). Web of Science and Scopus are not global databases of knowledge. SocArXiv. DOI: https://doi.org/10.31235/osf.io/qhvgr.

Walker, S. (2019). 'This is the golden age:' Eastern Europe's extraordinary 30-year revival. The Guardian, October 26, 2019. https://www.theguardian.com/world/2019/ oct/26/this-is-the-golden-age-easterneuropes-extraordinary-30-year-revival.

Walters, W.H. (2917). Citation-Based Journal Rankings: Key Questions, Metrics, and Data Sources. IEEE Access, vol. 5, pp. 2203622053. DOI: 10.1109/ACCESS.2017.2761400.

\section{ABOUT THE AUTHORS}

Tomas M. Krueger, email: thomas.krueger@tamuk.edu

Dr. Thomas M. Krueger (B.S.-Business Education, MBA, DBA) is an Endowed Professor, Chair of our Finance and Accounting Department, Chair of the College of Business Administration's Faculty Development Committee, and Chair of the Faculty Senate's Faculty Evaluation Committee at Texas A\&M UniversityKingsville. Dr. Krueger is also well known and respected for his research in finance nationally and internationally. As of June 2020, Dr. Krueger has authored 80 articles appearing in refereed journals, which have been cited, in aggregate, over 1200 times. He is currently Associate Editor of the Journal of Finance Issues, and editor of the Refereed Proceedings of the Academy of Finance.

Dr. Nikolay Megits is an Adjunct Professor at Webster University, St. Louis, MO, teaching Macroeconomics and Business courses. He holds an MBA and a Doctorate in Economics. Dr. Megits is an Academic of the Ukrainian Academy of Economic Sciences. Through his extensive business experience and academic career, Dr. Megits acquired significant expertise in the fields of strategic management, global economics, FDI in emerging markets, and entrepreneurship. In addition to this, he has a strong record in both lecturing and research with over 30 years of international business experience, which includes international economics, sales, and import/export practices. 